\title{
NARRATIVAS SOBRE O NAZISMO E O FASCISMO NAS COLEÇÕES DIDÁTICAS DE HISTÓRIA - SABER ESCOLAR E DEMANDAS DO TEMPO PRESENTE
}

\author{
Maria Aparecida da Silva Cabral ${ }^{1}$ \\ Marilu de Freitas Faricelli ${ }^{2}$
}

\begin{abstract}
Resumo: As narrativas sobre os temas do nazismo e do fascismo, as quais estão presentes em dois livros didáticos de História organizados em coleções didáticas destinadas ao terceiro ano do Ensino Médio e aprovados no Programa Nacional do Livro Didático (PNLD) de 2018, são analisadas neste artigo. Interessa-nos compreender que articulações são produzidas pelos autores desses materiais em relação às demandas do tempo presente, decisivas na conformação dos saberes históricos escolares, e que interlocuções são feitas com o conhecimento historiográfico. Constata-se que os caminhos trilhados pelos autores de tais livros didáticos não somente respondem aos critérios definidos por esse programa para a área de História em diálogo com as prescrições curriculares para a história escolar, mas também apontam para os diversos projetos historiográficos em circulação no âmbito da ciência de referência, que são norteadores de sua construção.
\end{abstract}

Palavras-chave: Ensino de História. Livro didático. Currículo. Nazismo. Fascismo.

\section{NARRATIVES ABOUT NAZISM AND FASCISM IN THE DIDACTIC COLLECTIONS OF HISTORY - SCHOOL KNOWLEDGE AND DEMANDS OF THE PRESENT TIME}

\begin{abstract}
In this article was analyzed, narratives on the themes of Nazism and Fascism, present in two history didactics books organized in didactic collections of the third year of high school and approved in the National Didactic Book Program (PNLD) 2018. We were interested in understanding what articulations were produced by the authors of these materials to the demands of the present time, which are too decisive in shaping school historical knowledge, and what interlocutions were made with historiographic knowledge. It appears that the paths followed by the authors of such didactics books not only responds to the criteria defined by this program for the area of History in dialogue with the curriculum prescriptions for school history but also point to the various historiographic projects in circulation within the scope reference science, which guide its construction.
\end{abstract}

Keywords: History teaching. Didactic book. Curriculum. Nazism. Fascism.

\footnotetext{
${ }^{1}$ Professora Adjunta da Faculdade de Formação de Professores da Universidade do Estado do Rio de Janeiro, Curso Licenciatura em História e Mestrado Profissional em Ensino de História (Profhistória). Mestrado e Doutorado em Educação na Pontifícia Universidade Católica de São Paulo. Pesquisadora do Grupo Interinstitucional Oficinas de História.

${ }^{2}$ Possui graduação em História pela Universidade de São Paulo (1985), graduação em Licenciatura em História pela Universidade de São Paulo (1986) e mestrado em Educação: História, Política, Sociedade pela Pontifícia Universidade Católica de São Paulo (2004). Atualmente é doutoranda do Programa Educação, História, política e Sociedade da PUC-SP. No Colégio Humboldt de São Paulo foi responsável pela elaboração do currículo bicultural, português e alemão, de História, elaborado entre os anos de 2016 e 2017.
} 


\section{RÉCITS SUR LE NAZISME ET LE FASCISME DANS LES COLLECTIONS DIDACTIQUES DE L'HISTOIRE - CONNAISSANCES SCOLAIRES ET EXIGENCES DU TEMPS PRÉSENT}

Résumé: Les récits sur les thèmes du nazisme et du fascisme, qui sont présents dans deux manuels d'histoire organisés dans des collections didactiques pour la troisième année de lycée et approuvés dans le Programme national des manuels scolaires (PNLD) 2018, sont analysés dans cet article. Nous nous intéressons à comprendre quelles articulations sont produites par les auteurs de ces matériaux par rapport aux exigences du temps présent, décisives dans la conformation des connaissances historiques de l'école, et que les interlocutions sont faites avec des connaissances historiographiques. Il est observé que les voies empruntées par les auteurs de ces manuels répondent non seulement aux critères définis par ce programme pour le domaine de l'Histoire en dialogue avec les prescriptions scolaires pour l'histoire de l'école, mais pointent également vers les différents projets historiographiques en circulation dans le cadre de la science de référence, qui guident sa construction.

Mots clés: L'enseignement de l'histoire. Manuel. Programme d'études. Le nazisme. Fascisme.

\section{NARRATIVAS SOBRE EL NAZISMO Y EL FASCISMO EN LAS COLECCIONES DIDÁCTICAS DE HISTORIA - CONOCIMIENTOS ESCOLARES Y DEMANDAS DE LA ACTUALIDAD}

Resumen: Las narrativas sobre los temas del nazismo y el fascismo, que están presentes en dos libros de texto de Historia organizados en colecciones didácticas para el tercer año de la escuela secundaria y aprobados en el Programa Nacional del Libro Didáctico (PNLD) 2018, son analizadas en este artículo. Nos interesa entender qué articulaciones son producidas por los autores de los materiales en relación con las exigencias de la actualidad, decisivas en la conformación del conocimiento histórico escolar, y qué interlocuciones se realizan con conocimiento historiográfico. Se observa que los caminos tomados por los autores de los libros de texto analizados no sólo cumplen con los criterios definidos por este programa para el área de Historia en diálogo con las prescripciones curriculares para la historia escolar, sino también apuntan a los diversos proyectos historiográficos en circulación dentro del ámbito de la ciencia de referencia, que están guiando su construcción.

Palabras clave: Enseñanza de historia. Libro de texto. Currículo. Nazismo. Fascismo.

\section{Introdução}

Em 2019, desde o início do governo de Jair Bolsonaro, as experiências autoritárias como a Ditadura Militar no Brasil, o Fascismo e o Nazismo têm sido revisitadas, ressignificadas e se tornado presentes em incontáveis atos, falas e textos divulgados nas mídias sociais, configurando uma intensa "guerra de narrativas" ${ }^{3}$. Em meados de 2020, enquanto o Brasil e o mundo se veem amargurados por questões sanitárias prementes, análises e comentários políticos referem-se constantemente ao Nazismo - autoridades governamentais, ministros, presidente da República, jornalistas

\footnotetext{
${ }^{3}$ Usamos essa expressão de Christian Laville (1999), cunhada em sua análise sobre o ensino de história, para enfatizar as lutas que se travam em torno das representações do passado e os setores sociais com os quais se relacionam.
} 
políticos, intelectuais e cientistas de diversas áreas se valem de acontecimentos daquele momento para adjetivar situações vividas no presente (ARAÚJO, 2019).

A inclusão do tema na agenda política brasileira aconteceu já antes da eleição e se tornou corriqueira no debate político em diversos momentos. Como personificação do mal, o acontecimento passa a representar o perigo iminente. O fato histórico descontextualizado e recortado passou a ser utilizado na construção de uma narrativa na qual o medo e a violência imperam. Nesse momento, o fato do passado, retirado de seu contexto, manipulado segundo interesses e embates políticos, conforma uma memória coletiva (LE GOFF, 1990), transformada em palco de disputa política em que o complexo processo histórico passa a ter significado simplificador e ameaçador.

Esse fenômeno não é algo novo. Pode ser observado com a ascensão das correntes revisionistas no campo do conhecimento e do movimento negacionista, disseminadas em mídias sociais há algum tempo (ROQUE, 2020) ${ }^{4}$. A negação do Holocausto, por exemplo, tornou-se bandeira defendida por diversos estudiosos (NAQUET, 1988). Dentre eles, destaca-se David Irving, que processou a historiadora americana Deborah Lipstad, nos anos de 1990, em tribunal inglês, em razão da publicação do livro Denying the Holocausto: the growing assault on truth and memory (Negando o Holocausto: o crescente ataque à verdade e à memória), o qual compilava vários trabalhos que negavam o massacre de judeus ${ }^{5}$.

Diante desse cenário, alertas se acendem aos profissionais que trabalham com a história ensinada ${ }^{6}-$ a que demandas sociais do presente essas narrativas correspondem? Qual seria o papel dos professores na problematização dessas questões em sala de aula? E como os conteúdos apresentados em materiais didáticos, especificamente nos livros didáticos de História, têm tratado esses temas?

De grande relevância para a compreensão do século $\mathrm{XX}$, o Nazismo e o Fascismo, ou Nazifascismo, têm se constituído assunto obrigatório no currículo histórico escolar no ensino fundamental e médio há pelo menos setenta anos. Trata-se

\footnotetext{
${ }^{4}$ Recentemente na Revista Piaú́, o texto de Tatiana Roque remete a um movimento de descrença em relação ao conhecimento científico e às ações políticas, capitaneado por lideranças de ultradireita no cenário nacional e internacional, denominado de negacionismo ou pós-verdade. Nesse fenômeno, experiências vividas e convicções são valorizadas em detrimento das evidências e dos consensos científicos.

${ }^{5}$ O filme Denial (Negação), do diretor Mick Jackson, divulga o fato em 2016.

${ }^{6}$ Denominamos história ensinada o conhecimento histórico de natureza escolar voltado à formação de crianças, adolescentes e jovens em situação de escolarização. A título de esclarecimento, informamos que, neste artigo, os termos história escolar e ensino de história são usados com a mesma finalidade.
} 
de um tema sensível ${ }^{7}$ porque concretamente apresenta a experiência de dor e de sofrimento de um conjunto de pessoas perseguidas, presas e mortas. Examinar esse processo histórico em suas inúmeras facetas é essencial para entender acontecimentos como a Segunda Guerra Mundial, a guerra entre países capitalistas e socialistas, a emergência dos EUA como potência mundial etc. Outrossim, questões cotidianas atuais relacionadas ao racismo, ao nacionalismo, ao uso político da propaganda política, à disseminação de fake news e à importância da convivência democrática permanecem mostrando a urgência de revisitar esse passado de intransigência e opressão. A opção por esse assunto na disciplina de História do ensino médio não ocorre por acaso nas coleções didáticas. Em nossa percepção, como professoras dessa área de conhecimento, tais temas se tornam imprescindíveis para a formação histórica de estudantes brasileiros no tocante à compreensão dos direitos humanos, fundamentais para o exercício da cidadania, ainda tão desafiante ao contexto brasileiro (FORQUIN, 1992).

Instigadas pelas reflexões de estudiosos do campo do currículo (GOODSON, 1997; SACRISTÁN, 2000), da história das disciplinas escolares (CHERVEL, 1990) e do livro didático (CHOPPIN, 2002, 2004, 2009; BITTENCOURT, 2006, 2008a, 2011; MUNAKATA, 2012, 2016), almejamos problematizar as operações realizadas pelos autores de livros didáticos na construção de suas narrativas, conformadas no formato de capítulos, em coleções didáticas aprovadas pelo Estado brasileiro, por meio do Programa Nacional do Livro Didático - PNLD $^{8}$. Interessa-nos indagar os modos como os olhares sobre o passado se transformam em conteúdos ensináveis aos estudantes da educação básica. Que articulações são tecidas entre as demandas sociais, os conteúdos históricos da tradição escolar e os saberes da ciência de referência na conformação de tais narrativas?

Elegemos como objeto dessa discussão as narrativas históricas sobre os temas do Nazismo e do Fascismo presentes nos livros didáticos de História com a intenção de responder a questionamentos a respeito das representações sociais (CHARTIER, 1990) que estão legitimadas nesse material. Nosso foco são as articulações produzidas por seus autores no entendimento das demandas do tempo presente (ROCHA et al., 2009), decisivas na conformação dos currículos escolares (FORQUIN, 1992; SACRISTÁN, 2000), e suas interlocuções com o conhecimento historiográfico (MONTEIRO, 2001).

\footnotetext{
7 Cabe enfatizar que os temas sensíveis, ou traumáticos, têm sido cada vez mais revisitados pelos pesquisadores que atuam no campo do ensino de História. Para aprofundar essa discussão, conferir os trabalhos de Alberti (2014) e Pereira e Seffner (2018).

${ }^{8}$ Utilizam-se as Coleções Oficinas da História, da Editora Leya, e História, da Editora Saraiva.
} 
Mobilizamos, para isso, o conceito de narrativa com base na perspectiva de Ricouer (1994), entendida por meio da representação da ação e do agenciamento dos fatos em uma intriga.

É por meio da narrativa que podemos apreender a recriação do sentido. Além disso, ela é uma possibilidade de articulação entre linguagem e experiência humana no tempo. Cabe esclarecer que as narrativas históricas apresentadas nos livros didáticos em análise neste artigo estão sendo compreendidas para além do texto principal. A nossa opção foi considerar todos os elementos que dão formato ao texto, incluindo imagens, questões problematizadoras, exercícios e referências escritas e visuais, reunidos no formato de capítulo, que dá organização a uma unidade temporal. Um outro elemento que nos ajuda a refletir sobre a construção dessa narrativa histórica escolar é a memória, caracterizada aqui por atos de lembranças e esquecimentos feitos por movimentos seletivos entre passado e presente (LE GOFF, 1990), pois, com a revisão do currículo da disciplina escolar História dos últimos anos, representações canônicas foram questionadas e revistas, transformando o debate em campo de batalha.

\section{Coleções didáticas de História em análise}

Como elementos fundamentais da cultura escolar ${ }^{9}$, os livros didáticos de História estão presentes nas escolas de nosso país desde o século XIX (BITTENCOURT, 2008a). Destinados ao uso escolar, são suportes privilegiados dos conteúdos educativos porque veiculam conhecimentos e técnicas considerados necessários à formação de novas gerações (CHOPPIN, 2004), atendendo a finalidades educativas estabelecidas socialmente (CHERVEL, 1990).

Choppin (2009, p. 533) nos ensina que os livros didáticos nos ambientes educativos cumprem quatro funções distintas. A primeira delas é referencial ou curricular, que trata da apresentação do que deve ser ensinado às futuras gerações, a partir de uma seleção realizada socialmente em constantes embates em torno do que deve ser transmitido às gerações mais jovens. A segunda, a instrumental, versa sobre os métodos de aprendizagem ou a proposição de atividades voltadas à aquisição de competências disciplinares. A ideológica e cultural, que é a terceira função, aborda aspectos relacionados à produção de subjetividades dos indivíduos em processos

\footnotetext{
9 Neste artigo, fazemos uso da categoria cultura escolar, bastante mobilizada nos estudos de livros didáticos, em consonância com a perspectiva de Julia (2001), que a considera como um conjunto de concepções, normas e práticas.
} 
formativos, e a última, que é a documental, incide sobre um conjunto de informações e documentos que constituem o roteiro de ensino e aprendizagem desse material. Em suas reflexões acerca desse rico material, o autor chama a atenção para a necessidade de se pensar os processos de produção, circulação e uso por professores e alunos.

No processo da escolarização moderna que impulsionou a construção de currículos escolares, os livros didáticos de História tornaram-se decisivos na produção e divulgação de conteúdos e métodos históricos, contribuindo na formação de uma tradição escolar. Ao elegermos os livros didáticos como fontes documentais privilegiadas para a discussão da temática do Nazismo e do Fascismo no ensino da História, destacamos a centralidade dessa fonte no entendimento do que é cotidianamente tratado em sala de aula, mobilizando memórias da comunidade escolar e sentidos de História.

Nesse sentido, concordamos com as reflexões de Miranda (2012), segundo a qual os livros didáticos de História devem ser pensados para além de sua função didática, pois as informações sobre tempo e suas marcações nesses suportes configuram uma linguagem particular que deve ser lida e interpretada no diálogo com imagens e demais conteúdos. Argumenta a autora:

Ao serem dados a ler durante o processo de escolarização, esses textos complexos se convertem em marcadores culturais que fazem circular discursos hegemônicos, socialmente referendados e repetidos por força do código disciplinar. Em primeiro lugar, o texto-base e a organização dos capítulos indicam agrupamentos temáticos apresentados em torno de um programa selecionado - o que provoca escolhas relacionadas ao tempo e aos espaços abordados -, e que constituem, por força da organização sequencial dos capítulos vinculados a esses recortes, determinadas perspectivas compreensivas quanto à sucessão (MIRANDA, 2012, p. 249).

Embora permaneçam muito presentes como suporte de aprendizagem escolar, os livros didáticos de História do século $\mathrm{XXI}^{10}$ são bem diferentes dos compêndios que circularam entre o século XIX e a primeira metade do século XX. Os materiais atuais investem em apresentação estética para estimular práticas de leitura para crianças no suporte impresso, em um mundo que cada vez mais prioriza o acesso a textos por meios

\footnotetext{
${ }^{10}$ O livro didático contemporâneo brasileiro é resultado de um projeto gráfico-editorial distribuído em três itens: estrutura editorial, projeto gráfico e ilustrações. De acordo com a exigências do Edital PNLD 2018, a estrutura editorial deve valorizar uma disposição clara, coerente e funcional em consonância com os objetivos didático-pedagógicos adequados à idade dos estudantes; os sumários devem garantir uma rápida localização das informações por meio da apresentação de informações claras e organizadas; e o projeto gráfico deve se preocupar com o tamanho e o espaçamento das letras, estar isento de erros gráficos e indicar leituras complementares, além de disponibilizar referências bibliográficas.
} 
eletrônicos e virtuais. Esses livros usam e abusam de cores, estilos de letras, boxes e iconografia, observáveis na organização espacial do texto explicativo principal, sempre acompanhado por diversos recursos, tais como excertos de produções historiográficas e outros textos, hipertextos, glossários, imagens, mapas, exercícios diversos, esquemas explicativos e fontes históricas primárias. São materiais elaborados a muitas mãos, resultado de um complexo processo de produção (BITTENCOURT, 2008; MUNAKATA, 2012), que precisa ser compreendido na sua relação com a cultura escolar (MUNAKATA, 2016).

No campo do ensino de história, os livros didáticos têm sido uma temática constante nas investigações nos últimos anos, sendo objeto de pesquisadores individuais e grupos de pesquisas no Brasil e no exterior. As pesquisas de Circe Bittencourt e Kazumi Munakata nos anos de 1990 e, mais recentemente, as de Célia Cassiano (2013) e Adriana Ralejo (2018), no início do século XXI, apontam para a complexidade da produção do livro didático, ao mostrarem a relação entre as agências e os agentes com o Estado Brasileiro ${ }^{11}$.

Uma outra tendência que tem se fortalecido nos estudos de livros didáticos de História é a problematização das narrativas difundidas nesses materiais, com foco na compreensão das articulações tecidas entre conhecimento escolar e historiografia, assim como as questões que tangenciam a produção dos currículos, as lutas por direitos sociais e a reivindicação de outras representações de negros, indígenas e mulheres. Preocupada em construir caminhos que promovam diálogos frutíferos entre o conhecimento acadêmico e os livros didáticos de História, Rocha (2017) destaca que:

A complexidade dos conteúdos narrados nos livros didáticos remete à natureza própria do conhecimento histórico no currículo escolar. As pesquisas no âmbito do ensino de história, assim como de outras disciplinas dos últimos 20 anos, por diferentes caminhos, apontam para essa natureza, mostrando que, seja pela importância da cultura constituída nesse espaço e a organização que lhe é correlata na escola, seja pela ação dos docentes na apropriação e síntese de um conjunto que incluí currículos, formação acadêmica e materiais de ensino para a realização do seu trabalho, o conhecimento do currículo escolar de qualquer

\footnotetext{
11 Tomando Choppin (2002, 2004, 2009) como referência em suas investigações acerca de livros didáticos, Bittencourt e Munakata consideram o livro didático como um objeto da indústria cultural, produzido por vários sujeitos: editores, autores, técnicos especializados em gráficos, programadores visuais, ilustradores etc. Cassiano (2013) analisa a construção de políticas públicas educacionais direcionadas ao livro escolar, com foco na história do PNLD e sua relação com mercado editorial brasileiro. Ralejo (2018) se preocupa em problematizar o lugar de autoria na produção de livros didáticos de História, em um contexto em que o papel do autor tem sido ressignificado. Segundo a autora, o acirramento das disputas do mercado editorial, que levam à produção cada vez mais acelerada desses materiais, e a constituição de equipes superespecializadas nos processos de formatação final do livro redirecionam o lugar desse autor (ou autores) na construção da obra didática.
} 
disciplina é um conhecimento heteróclito, resultado de diferentes referências, que atende as finalidades escolares de ensino e aprendizagem de cada disciplina. (ROCHA, 2017, p. 19).

É válido ressaltar que a compreensão do conhecimento histórico escolar (BITTENCOURT, 2006; MIRANDA; DE LUCA, 2004; MONTEIRO, 2001; ROCHA, 2017) como resultado de múltiplas referências tem sido cada vez mais recorrente nos estudos que tematizam a produção de currículos, livros didáticos, saberes e fazeres docentes e discentes nas pesquisas em ensino de História. Nessa perspectiva, Miranda e De Luca (2004, p. 134) advertem que a problematização da natureza do saber histórico escolar não pode desconsiderar as suas diversas faces, porque envolve prescrição e mobiliza representações "sem desprezar os processos objetivos de apreensão do conhecimento histórico pelos alunos e a construção de conceitos dele derivados".

A respeito das coleções didáticas que chegam aos estudantes brasileiros, um primeiro aspecto a ser considerado é o papel do Estado na gestão de políticas públicas educacionais sobre esses materiais de ensino. O PNLD foi criado em 1985 e implementado no ano seguinte com a finalidade de avaliar os livros didáticos a serem distribuídos nas escolas públicas brasileiras pelo governo federal. Esse programa estabelece parâmetros para a avaliação de acordo com a legislação nacional e com os critérios das áreas disciplinares divulgados por meio de editais e portarias, que são observados por editoras, autores, comissão avaliadora, professores da educação básica e gestores educacionais ${ }^{12}$.

Trata-se de um processo bastante complexo, iniciado com a publicação de um edital feito pela comissão técnica do MEC, o qual dispõe sobre o chamamento público de inscrição de autores e editores. Nesse documento, são explicitadas as exigências a serem cumpridas em relação a conteúdos, métodos, organização e textos de orientação a professores e é indicada a legislação que norteia a construção de currículos da educação básica. Em seguida, há o processo de contratação de universidades, realizada também por meio de chamada pública ${ }^{13}$.

O próximo momento é o encaminhamento desses materiais às escolas de educação básica, que organizam reuniões por áreas de conhecimento, convocando seus professores a escolherem os materiais aprovados pela equipe de especialistas dos MEC.

\footnotetext{
${ }^{12}$ Registramos aqui que as pesquisas sobre o PNLD (área História) são cada vez mais presentes no campo de estudos do ensino de História no Brasil. Estas mereceriam uma seção específica, que não será possível realizar neste artigo, em razão do nosso recorte acerca das narrativas didáticas.

${ }^{13}$ No caso da avaliação do PNLD de 2018, a Universidade Federal de Sergipe foi selecionada para ser a instituição responsável pela avaliação (BRASIL, 2018, p. 12).
} 
Após a definição dos professores, a escola encaminha toda a documentação para a secretaria de educação à qual se vincula para que os alunos recebam os livros no início do ano letivo.

Como todas as editoras e autores atendem aos editais públicos, nos quais se apresentam os critérios de avaliação a todas as áreas, assim como ao componente específico História ${ }^{14}$, uma primeira característica geral a todos os livros didáticos é a presença de um pequeno texto introdutório para apresentar a obra ao público leitor. $\mathrm{O}$ texto apresenta os objetivos pedagógicos da coleção, os caminhos adotados na seleção e organização de temas, bem como suas interpretações sobre a importância do estudo da disciplina.

Os dois livros escolhidos para esta análise, organizados em coleções didáticas, foram avaliados no PNLD de $2018^{15}$, estando em uso por estudantes nas escolas públicas brasileiras no terceiro ano do Ensino Médio. Abarcam o período contemporâneo estabelecendo como recorte o início do século XX até os dias atuais e integrando os conteúdos históricos nacionais aos gerais. Embora cada coleção didática desenvolva seu próprio projeto editorial, todas atendem aos parâmetros estabelecidos.

De um total de dezenove aprovações no PNLD de 2018, selecionamos dois livros para examinar, produzidos por historiadores reconhecidos no campo da História por suas investigações. O primeiro livro, da coleção História, Editora Saraiva, tem a autoria coletiva dos pesquisadores/professores Ronaldo Vainfas, Sheila de Castro Faria, Jorge Ferreira e Georgina dos Santos, vinculados ao Departamento de História da UFF. Já o segundo livro, da coleção Oficinas de História, Editora Leya, é elaborado por dois pesquisadores/professores do Departamento de História da USP, Flávio de Campos e Júlio Pimentel, e por uma autora de livros didáticos e paradidáticos, Regina Claro, que desenvolve projetos de capacitação de professores da rede pública em atendimento às Leis n. ${ }^{\circ} 10.639$, de 2003, e n. ${ }^{o} 11.645$, de $2008^{16}$.

\footnotetext{
${ }^{14}$ A esse respeito, ver o Guia PNLD 2018. Disponível em: http://www.fnde.gov.br/pnld-2018/. Acesso em: 1 ago. 2020.

${ }^{15}$ O Edital que orientou esse PNLD foi publicado em 2015. As informações desse processo podem ser acessadas no endereço eletrônico do Fundo Nacional de Desenvolvimento para a Educação - FNDE. Disponível em: https://www.fnde.gov.br/index.php/programas/programas-do-livro/pnld/guia-do-livrodidatico/item/11148-guia-pnld-2018. Acesso: 14 jun. 2020.

${ }^{16}$ Ambas as leis modificam a Lei de Diretrizes e Bases da Educação Nacional, n. ${ }^{\circ}$ 9.394/1996, em seu artigo 26-A. A primeira trata da obrigatoriedade do ensino da História da África e da cultura afrobrasileira nos currículos de estudos da educação básica. Já a segunda acrescenta a temática indígena, instituindo-a como obrigatória a partir de 2008 , passando a vigorar a seguinte redação no caput: "nos estabelecimentos de ensino fundamental e de ensino médio, públicos e privados, torna-se obrigatório o estudo da história e cultura afro-brasileira e indígena” (BRASIL, 2008).
} 
Três razões nos motivaram a selecionar essas duas coleções. A primeira delas é o fato de verificarmos sua presença em muitas escolas públicas e privadas nos estados de São Paulo e Rio de Janeiro, locais de nossa inserção profissional como professoras e pesquisadoras. A segunda razão é a quantidade de investigações no campo do ensino de História que elegem essas obras como objeto de análise E a última razão é a inserção acadêmica de seus autores.

\section{Narrativas sobre Nazismo e Fascismo nas coleções didáticas de História}

Os temas Nazismo e Fascismo são apresentados aos estudantes da educação básica brasileira em dois momentos do processo da escolarização: último ano do ensino fundamental, o nono ano, e terceiro ano do ensino médio. Nos livros didáticos de história atuais, tais temas são tratados por meio de uma narrativa principal (texto-base), fontes documentais escritas e imagéticas, informações complementares e atividades didáticas articuladas em capítulos.

$\mathrm{Na}$ tradição curricular da história escolar, esses temas são ensinados cronologicamente aos estudantes com o objetivo de apresentar a ascensão dos regimes totalitários relacionando-os à conjuntura política no pós-Primeira Guerra Mundial, suas consequências econômicas e sociais para diversos países europeus e para os Estados Unidos da América, e, por fim, à eclosão da Segunda Guerra Mundial em 1939 ${ }^{17}$. Com a expectativa de produzir entendimentos acerca desse período, tido por muitos estudiosos como um dos mais emblemáticos da história, textos e imagens são mobilizados para que os estudantes compreendam esse conflito mundial.

Uma outra questão que não pode ser desconsiderada nessa discussão - a respeito da ascensão do Fascismo na Itália e do Nazismo na Alemanha - é o valor pedagógico sinalizado na prescrição curricular para a história escolar quanto à dimensão cidadã. Na matriz de referências voltadas ao Exame Nacional de Ensino Médio (ENEM) para a área de Ciências Humanas e suas Tecnologias ${ }^{18}$, por exemplo, algumas competências indicam a necessidade de o estudante fazer uso das informações históricas no entendimento e na valorização dos fundamentos da cidadania e da democracia. Isso

\footnotetext{
${ }^{17}$ Ao analisar a estrutura do campo factual, Veyne (1998) alerta que um fato não pode ser pensando como um dado, mas sim como um cruzamento de itinerários possíveis, pois este é uma escolha do historiador. Nessa direção, argumenta o autor: "os historiadores narram tramas, que são tantas quantos forem os itinerários traçados livremente por eles" (VEYNE, 1998, p. 45).

${ }^{18} \mathrm{O}$ Componente Curricular de História faz parte dessa área, que concentra ainda Geografia, Sociologia e Filosofia.
} 
significa dizer que as narrativas didáticas produzidas nesse momento fazem mediações dos sentidos assumidos nos livros didáticos de história contemporâneos.

Construída com a finalidade de produzir sentido sobre o passado para as futuras gerações, a narrativa histórica escolar é (con)formada em um movimento de ressignificação do campo disciplinar de referência, à medida que mobiliza conceitos e procedimentos científicos do ofício do historiador; além disso, autores dos livros escolhidos, adotados e utilizados cotidianamente nas salas de aula, fazem apropriações e releituras das finalidades educativas e sociais, materializadas nos conteúdos e em sua didatização. No processo de escolarização de crianças, adolescentes e jovens, tal narrativa se converte em referenciais culturais e temporais à proporção que faz circular conteúdos legitimados socialmente e consensuados no campo disciplinar.

Desde o período da redemocratização brasileira nos anos de 1980, observamos que o reconhecimento da especificidade do saber histórico escolar aprimora as interlocuções realizadas com a disciplina de referência. De lá para cá, a construção de textos didáticos tem levado em consideração a incorporação de procedimentos teóricometodológicos, seja mediante valorização de usos documentais nas aulas de História e apresentação de recursos auxiliares, seja mediante incorporação de conceitos na narrativa histórica de natureza didática, como elementos articuladores de recortes temporais e espaciais. Torna-se importante sublinhar que a narrativa histórica escolar é construída a partir de várias tramas dispostas de maneira complementar no livro didático, objetivando a compreensão do contexto por parte dos alunos em diálogo com a área de referência e com os procedimentos metodológicos exigidos pelas prescrições oficiais a cada momento.

A escolha do conceito de narrativa, na perspectiva de Ricouer (1994), justificase porque é entendida por meio da representação da ação e do agenciamento dos fatos em uma intriga. É por meio da narrativa que podemos apreender a recriação dos sentidos. Além disso, ela é uma possibilidade de articulação da linguagem e da experiência humana no tempo. Por meio da análise das narrativas históricas presentes nesses livros didáticos, almejamos apreender "a invenção da intriga", à luz das reflexões de Ricouer (1994, p. 65) Essa ferramenta de análise potencializa a compreensão do encadeamento de episódios que se conectam em um todo. A composição da intriga, de acordo com o autor, faz "surgir o inteligível do acidental, o universal do singular, o necessário ou o verossímil do episódico" (RICOUER, 1994, p. 70). 
Em linhas gerais, nessas narrativas sobre o Fascismo e o Nazismo, há a intenção de se explicitar a contextualização do acontecimento histórico, pois a história ensinada se materializa pela disposição/apropriação de conceitos, construções de temporalidades, informações e valores relacionados à formação da cidadania. A forma como o tema é apresentado aos estudantes objetiva tornar inteligível esse período histórico, mobilizando, para isso, imagens e atividades problematizadoras que visam a provocar a desnaturalização das informações dispostas, trazendo à tona a ação dos sujeitos envolvidos nessa trama social.

Um movimento importante realizado por esses(as) autores(as) em tais coleções é a organização dos conteúdos no formato de temas que respondem a uma dada intepretação em torno do Fascismo e do Nazismo enquanto acontecimento histórico. Estes não são classificados como quaisquer ditaduras do século XX e, por isso mesmo, os autores enfatizam os processos sociais que possibilitaram o surgimento de tais regimes, as bases sociais que os sustentaram politicamente e as estratégias usadas pelos sujeitos históricos para alcançar os seus objetivos.

Além disso, o papel da liderança de Benito Mussolini, na Itália, e de Adolf Hitler, na Alemanha, ganha destaque nessas narrativas. No livro História, a abertura do capítulo intitulado $O$ fascismo e o nazismo contra a democracia e o socialismo visa a mostrar de que maneira Mussolini, na Itália, e Hitler, na Alemanha, lideraram regimes que se opuseram à democracia e ao socialismo e que contexto histórico possibilitou a origem de tais regimes instituídos à base de violência e terror por meio da perseguição aos diferentes. No caso da obra Oficina da História, os autores indicam, já na primeira frase do capítulo, que se trata do poder pessoal de Mussolini, apoiado por incontáveis seguidores, caracterizando assim o momento histórico: “culto à força, à violência e à hierarquia, militarismo, intolerância diante das opiniões diversas, valorização do autoritarismo" (CAMPOS, et al., 2016 p. 65).

Os termos fascismo e nazismo no livro História são conectados aos contextos históricos dos quais emergem, sendo entendidos como processos históricos. Apesar de esses dois regimes serem caracterizados como experiências de governos ditatoriais, verificamos que, nessas narrativas históricas de natureza escolar, o fascismo relacionase ao caso italiano, sob a liderança de Benito Mussolini, e o nazismo ao caso alemão, de Adolf Hitler. Destacamos que a opção metodológica de Vainfas et al. (2016) é apresentar cronologicamente os eventos que constituíram o regime fascista na Itália, abordando a criação do partido fascista, a marcha sobre Roma, a perseguição aos 
opositores e a chegada ao poder de Mussolini, e, em seguida, trazer o tema do nazismo na Alemanha, enfatizando a criação do partido nacional-socialista (ou nazista), a ascensão de Hitler com a adesão das classes dominantes à ideologia nazista, a criação dos campos de concentração e a perseguição aos opositores, principalmente ao povo judeu.

Já Campos et al. (2016) apresentam linha do tempo vertical com fatos da história da Alemanha e da Itália de 1918 a 1933, tradicionalmente relacionados à "emergência do totalitarismo", com alguns destaques - "1922 - Marcha dos fascistas sobre Roma; 1923 - Inflação alemã e Hitler é preso após o fracassado 'putsch da cervejaria'; 1924 Partido Fascista obtém vitória eleitoras na Itália” (CAMPOS et al., 2016, p. 65) -, tornando o Fascismo e o Nazismo fatos entendidos como parte do mesmo processo totalitário. Assim, é possível ao aluno entender os fatos ocorridos em cada um dos países num contexto mais abrangente.

Objeto de estudo em diversas áreas de conhecimento, o fascismo tem sido pensado como uma reação ao liberalismo e ao socialismo - "Há um consenso entre pesquisadores de que este fenômeno tem muito a ver com a chamada sociedade de massas e de que deve ser situado especialmente na Alemanha e na Itália" (SILVA, 2006, p. 141). Embora o uso do conceito de fascismo tenha sido mobilizado na explicação de um conjunto de experiências autoritárias no século $\mathrm{XX}$, tanto no continente europeu quanto na América Latina, Ásia e África, cabe esclarecer que este foi pensado a partir do contexto histórico que o fez emergir. O fascismo, na perspectiva de Hobsbawm (1995 apud SILVA, 2006, p. 142), em suas versões italiana e alemã, é caracterizado por uma intensa mobilização das massas, pela defesa ferrenha dos valores tradicionais em contraposição às ideias modernas e pela recriação do passado e invenções de tradições, além de seu papel contrarrevolucionário.

Nessas coleções didáticas, o totalitarismo $^{19}$ explica a associação e as especificidades desses regimes em um contexto mais amplo, relacionando fatos históricos ocorridos em diversos espaços. Especificidades das instituições escolares tornam a cultura escolar algo produzido e transmitido pelas, para e nas instituições escolares. São inúmeras as possibilidades de dar sentido a esse momento da história da Humanidade.

\footnotetext{
${ }^{19}$ Esse termo foi utilizado pela primeira vez na Enciclopédia Italiana, em 1932, segundo Stoppino (1998, p. 1241), para designar o "partido que governa totalitariamente uma nação", enquanto, durante o governo de Hitler na Alemanha, o termo mais utilizado foi Estado autoritário. Sua utilização como conceito definidor de ditaduras fascistas ou comunistas se tornou comum após a Segunda Guerra Mundial.
} 
As coleções analisadas divulgam o conceito de totalitarismo em diálogo com as reflexões de Hannah Arendt, considerada uma autora marcante nesse debate ${ }^{20}$. De acordo com Arendt (1951 apud STOPPINO, 1998) o totalitarismo consolida-se no século XX como um fenômeno radicalmente diferente das tiranias anteriores e do antigo despotismo, porque visa justamente à destruição dos próprios grupos sociais e das instituições, aniquilando com isso o próprio homem, "tornando-o estranho assim ao mundo e privando-o até de seu próprio eu" (STOPPINO, 1998, p. 1258).

No caso específico das coleções supracitadas, apesar de o totalitarismo ser mobilizado como elemento articulador das ações desencadeadas nos regimes fascista, na Itália, e nazista, na Alemanha, configurando-se como uma possibilidade interpretativa acerca de um determinado contexto histórico - a exemplo dos(as) autores(as) dessas coleções, os quais buscam assentar a representação dos atos humanos em narrativas -, lembramos que, para Arendt (1989 apud SILVA, 2006), tal conceito foi pensado para os casos da Alemanha nazista e da URSS, não se aplicando à Itália sob a liderança de Benito Mussolini, em razão de que, no caso italiano, o partido fascista não adquiriu a penetração em outras instituições sociais, a exemplo da magistratura, do exército e da burocracia estatal.

Assim, autores de livros didáticos, respondendo a diferentes demandas de seu tempo, como mercado, prescrições oficiais, imperativos didáticos, entre outras, e considerando seu próprio entendimento a respeito dos processos históricos e seu papel na formação das futuras gerações, fazem escolhas que, a nosso ver, serão fundamentais na (con)formação do saber histórico escolar.

\section{Caminhos adotados na apresentação e problematização dos temas pelos autores dos livros didáticos nas coleções de História}

\section{Coleção História}

Vainfas et al. (2016), no livro História, estabelecem como recorte temporal o período compreendido entre o início do século $\mathrm{XX}$ até os dias atuais. A tendência cronológica, linha temporal, predomina na organização dos temas e de seus respectivos espaços. Uma primeira observação é a forma como a relação entre o Brasil e os demais

\footnotetext{
${ }^{20}$ Para aprofundar esse assunto, recomenda-se o verbete Totalitarismo, na obra de Stoppino (1998, p. 1248). Em 1956, Carl J. Friedrich e Zbigiew K. Brzezibski, considerados divulgadores do termo totalitarismo, publicaram Totalitarismo e autocracia. Academicamente, há intensos debates sobre quais governos podem ser nominados como totalitários - para a própria Arendt (1989 apud SILVA, 2006, p. 141), o governo de Mussolini não se ajusta ao conceito.
} 
países é mencionada nesse livro. A opção dos autores em começar essa unidade com o processo da proclamação da República brasileira difere da clássica sequência que estabelece a História do Brasil após os acontecimentos internacionais ${ }^{21}$.

A respeito do projeto autoral e editorial desse livro, cabe destacar que todas as aberturas de unidades e capítulos são constituídas por temas aglutinadores que abordam tópicos do conteúdo selecionado, mas sem se limitar a ele. Especificamente nos capítulos, toda a temática é apresentada em textos que se articulam com imagens, glossários, indicações de filmes e páginas da internet, considerando a introdução do tema como abertura do capítulo, o desenvolvimento da narrativa e a seleção de imagens, focalizando a interpretação de textos e introduzindo a discussão de âmbito historiográfico, além da proposição de um roteiro de estudos. Esse tipo de abordagem visa a instrumentalizar os alunos em relação às habilidades a serem adquiridas na etapa do Ensino Médio. As questões de aprofundamento voltadas à cidadania, aos conflitos sociais, às representações do tempo, às linguagens etc. aparecem sob a rubrica Outra dimensão, que, nesse livro didático, tem a função de complementar as informações do texto principal. No caso do capítulo sobre o Nazismo e o Fascismo, contra a democracia e o socialismo, os autores, na abertura, publicam a fotografia de Adolf Hitler e Benito Mussolini juntos, em Munique no ano de 1937, retratando o momento que este último faz uma viagem à Alemanha nazista. É uma imagem que pode impactar o leitor, porque está em uma página de aproximadamente trinta centímetros - em seu tamanho original e ocupa praticamente oitenta e cinco por cento dela, conforme podemos observar na Figura abaixo:

Figura 1: Abertura de capítulo - Fotografia de Adolf Hitler e Benito Mussolini em 1937

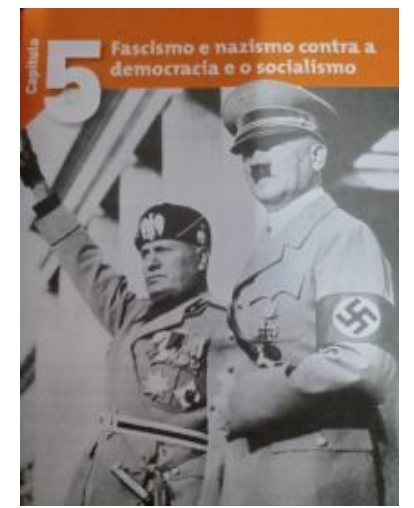

Fonte: Vainfas et al. (2016, p. 77)

\footnotetext{
${ }^{21}$ Elegemos, para exemplificação, a primeira parte do livro, denominada de Revoluções e guerras, que engloba a primeira metade do século XX, na qual se intercala uma discussão considerada na história escolar mais geral com a história dita nacional, isto é, a do Brasil, além de abarcar a temática que recortamos para nossa análise.
} 
O pequeno texto que acompanha essa imagem, apesar de ser bastante sintético, expressa bem as características principais do que foram esses regimes. Segundo os autores:

Benito Mussolini e Adolf Hitler lideram regimes na Itália e na Alemanha, respectivamente, que conspiraram contra a democracia, desafiaram o socialismo soviético e ainda puseram em marcha políticas de extermínio racial, sobretudo no caso nazista. É preciso conhecer essa história de perto - a origem desses movimentos, a tomada de poder, a organização policial de regimes baseados em violência e propaganda e terror (VAINFAS et al., 2016, p. 77).

Nas páginas seguintes, o fascismo na Itália é narrado em um texto que se divide em três subtemas: o fascismo em marcha, que enfatiza a "famosa Marcha sobre Roma", em 1922; a ditadura fascista, que narra o isolamento das oposições, a perseguição aos sindicatos e a ilegalidade dos partidos políticos, exceto o fascista em 1925; e o apogeu do fascismo, com a apresentação de várias ações e estratégias do governo fascista. Nessa parte do capítulo, logo na primeira página, apresenta-se uma definição de fascismo em um glossário, que, segundo os autores dessa coleção, almeja facilitar o estudo e a compreensão desse assunto ${ }^{22}$. Para fechar essa discussão sobre o fascismo, uma fonte documental (fragmento de uma mensagem de Mussolini, em 27 de outubro de 1930) é apresentada com uma questão sobre a forma como o fascismo estabeleceu relações entre o Estado e os indivíduos e entre os Estados e os grupos sociais. Ainda, em um quadro chamado Fique de Olho!, há a indicação do filme Mussolini, a história não contada (dirigido por Daniel Byrne, nos EUA, em 1985), que conta a biografia de Mussolini.

A narrativa que se estabelece acerca do Fascismo na Itália procura evidenciar o contexto histórico que possibilitou a sua ascensão. Os autores privilegiam começar o texto apresentando aos leitores as consequências da Primeira Guerra para esse país, com perdas políticas e prejuízos econômicos. Diversos sujeitos e grupos sociais são mobilizados nessa história a partir das ações que vão sendo encadeadas em uma relação de causalidade. Nessa perspectiva, os autores dedicam parte significativa do texto para explicar: a "efervescência política", como é chamada, atribuída ao crescimento do partido socialista italiano; a fundação do partido comunista da Itália, fruto da

\footnotetext{
${ }^{22}$ A palavra fascismo no texto principal é marcada na cor amarela. Na mesma página, ao lado esquerdo do texto, apresenta-se que fascismo "deriva do latim fascium, que na República Romana, significava insígnias do poder de Estado - 30 varas atadas por uma corda formando um cilindro que não se rompia" (VAINFAS et al., 2016, p. 78).
} 
dissidência do partido socialista; e o partido popular italiano, que capitalizou os grupos contrários ao socialismo. Assim, na sequência, organizam diversas cenas que vão dando um sentido à construção da ditadura fascista.

O Nazismo na Alemanha é apresentado em partes, assim intituladas: Surgimento do Nazismo, O nazismo alcança o poder, o Terceiro Reich, A propaganda nazista, Judeus perseguidos e Consolidação do nazismo. É interessante observar que os autores usam de uma estratégia discursiva recorrente nas narrativas históricas escolares para introduzir o assunto do nazismo na Alemanha quando se justifica a situação econômica desse país após a Primeira Guerra Mundial. A comparação com a situação da Itália, que também participou desse conflito, é consensual. Após ser apresentado o contexto político e a situação econômica da Alemanha, os autores sequenciam a próxima ação da seguinte forma: "foi nesse ambiente que se plantou a semente do nazismo, cujo embrião foi o minúsculo Partido dos Trabalhadores Alemães (Deutsche Arbeiterpartei), que pretendia representar a classe operária alemã rivalizando com os comunistas e os socialistas". (VAINFAS et al., 2016, p. 81).

O próximo assunto a ser tratado é a atuação de Hitler nesse partido e a adesão das classes dominantes ao Nazismo. A propaganda nazista ganha destaque nessa narrativa, sendo acompanhada por uma fotografia de 1935, na qual Hitler aparece com crianças e jovens alemães no canto direito de um texto sobre a atuação do Ministro Goebbels à frente do planejamento aos atos que celebravam o Führer e o próprio Nazismo. Abaixo, a Figura 2 apresenta Hitler junto com crianças brancas.

Figura 2: Abertura de capítulo - Fotografia de Adolf Hitler com crianças em 1935

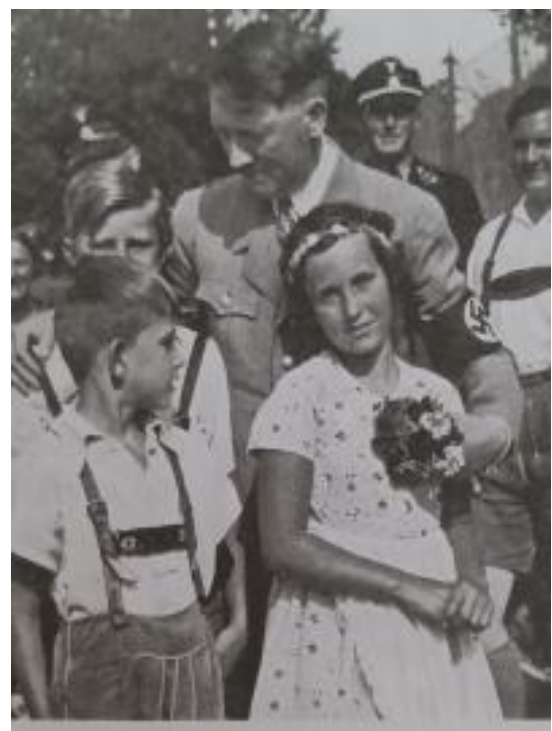

Fonte: Vainfas et al. (2016, p. 83) 
Na mesma página, duas questões são propostas aos estudantes com base na leitura de uma fonte documental escrita relacionada à Figura 3 - cartaz de propaganda eleitoral do partido Nazista de 1933 -, que representa os grupos tidos como inimigos do Nazismo. Os exercícios propostos, que compõem uma seção denominada Outra dimensão - Cultura, visando ao aprofundamento do tema relacionado à propaganda, referem-se à identificação de sujeitos e suas características e à análise das ações dos nazistas no poder:

Figura 3: Cartaz de propaganda nazista de 1933

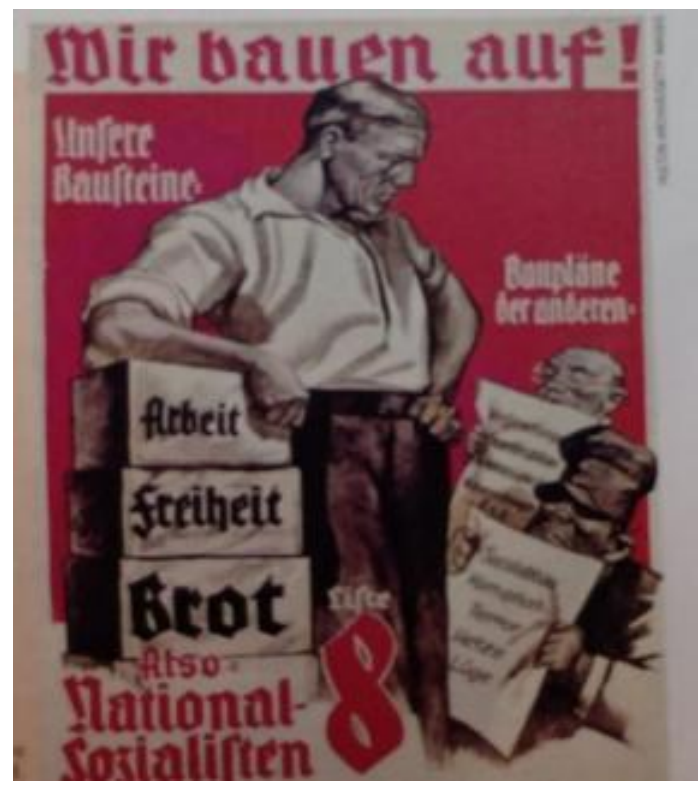

Fonte: Vainfas et al. (2016, p. 83)

Na página seguinte, há um investimento ainda na explicação de como se deu a perseguição aos judeus e aos demais opositores a esse regime totalitário. As experiências autoritárias de países europeus também são retratadas a partir de uma breve explanação sobre o que foi o Franquismo na Espanha e o Salazarismo em Portugal.

O capítulo é finalizado com uma proposição de roteiro de estudos com questões relacionadas aos textos e às imagens sobre a relação entre a temática do Nazismo e do Racismo, apresenta três questões de exames externos à instituição escolar (ENEM e Vestibulares) e conclui com uma atividade que visa a estabelecer uma conexão entre áreas do conhecimento com o recorte de um texto de Hannah Arendt sobre a construção e as características de um Estado Totalitário. 
DOI: $10.47694 /$ issn.2674-7758.v2.i5.2020.6691

\section{Oficina de História}

O volume 3 dessa coleção começa com um capítulo introdutório que retoma conceitos, fatos e o processo da industrialização e expansão europeia no contexto do Imperialismo. Na sequência, nove capítulos tratam da Primeira Guerra Mundial até os momentos atuais com títulos que caracterizam os temas tratados. Por exemplo, o primeiro capítulo, Guerra e revolução, trata a Primeira Guerra Mundial, a Revolução Socialista na Rússia e a Revolução Mexicana.

Os autores inovam em relação ao currículo integrado tradicional tratando de acontecimentos da América Latina, como a Revolução Mexicana, e da história da Argentina, lembrada como local de refúgio de nazistas durante o Peronismo. Pretendese, assim, construir um olhar global para a disciplina escolar, atendendo a um tempo atual no qual acontecimentos internacionais estão cada vez mais presentes.

$\mathrm{O}$ tema analisado está no capítulo denominado $\mathrm{O}$ destino bate à sua porta. Trata inicialmente do Brasil nos anos 1920, período denominado O Brasil entre o arcaico e o moderno. Segue com a Crise de 1929, o Fascismo e o Nazismo. Ao iniciar esse último item $^{23}$, Campos et al. (2016) utilizam o primeiro discurso de Benito Mussolini, feito em 1922 no parlamento italiano, para problematizar o que vão tratar no decorrer do texto didático. O documento disponibilizado dá veracidade ao que os alunos vão estudar e é a leitura realizada pelos autores da obra que determina seu significado: o discurso do líder italiano afirma "Eu poderia ter vencido completamente. Mas impus-me limites [...] Com 300 mil jovens armados dispostos a tudo e esperando minhas ordens em atitude mística”. Os autores destacam: "A referência à 'atitude mística' daqueles que aguardavam suas ordens expõe o anti-racionalismo e anti-intelectualismo dos fascistas, que insistiam que ação e crença deveriam substituir a razão e a reflexão" (CAMPOS et al., 2016 p.65). O texto-base permanece destacando nos boxes, na leitura complementar e na figura colorida o que os autores consideram relevante no estudo desse passado - a emoção que orienta os seguidores dos líderes como propaganda com objetivo de cooptação da população.

Roney Cytrynowicz, economista e historiador, é citado pelos autores, para conceituar a ideologia nazista, indicando a racionalidade da ação midiática nazista,

\footnotetext{
${ }^{23} \mathrm{Na}$ coleção, cada capítulo está dividido em itens numerados, nos quais são desenvolvidos os conteúdos conceituais.
} 
projetada para atingir aspectos irracionais das pessoas. A Figura 4 acompanha e materializa a definição.

Figura 4: Fotografia do Desfile em 1938

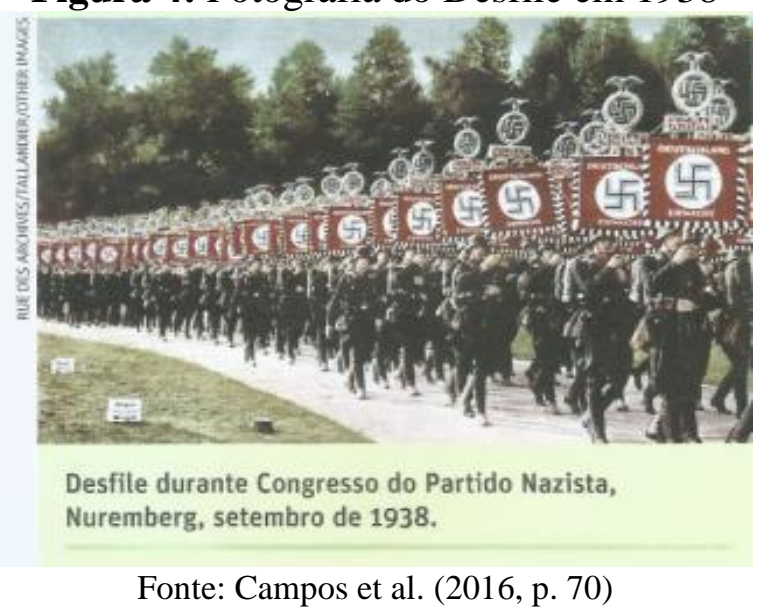

Ao final do texto-base, um trecho da obra Nazismo: o triunfo da vontade, de Alcir Lenharo, professor universitário, é indicado como leitura complementar e sugere trabalho interdisciplinar com a Sociologia sobre a relação entre massas e poder. O texto intitulado A celebração das massas reforça a discussão já iniciada sobre condução das massas:

Hitler atribuía grande importância psicológica a tais eventos, pois reforçavam o ânimo do militante nazista, que perdia o medo de estar só diante da força da imagem de uma comunidade maior, que lhe transmitia gratificantes sensações de encorajamento e reconforto. [...] O símbolo mágico da suástica, de conhecida ancestralidade, uma espécie de cruz em movimento, sugeria a energia, a luz, o caminho em sua rota. Reich viu-a dotada de conteúdo afetivo, e capaz de suscitar profundas emoções. (CAMPOS et al, 2016, p. 72).

Os exercícios retomam as intenções dos autores no uso do passado para formação discente - "Como emoção e racionalidade combinavam-se nas manifestações nazistas?" - e, ao mesmo tempo, relaciona-se essa leitura do vivido ao tempo presente "Nos dias atuais, quais são as circunstâncias em que ocorre o aparecimento do homemmassa?” (CAMPOS et al., 2016, p. 72).

A ascensão de Hitler ao poder é tratada também em sua relação com o fim das liberdades democráticas:

O processo de centralização política e supressão dos direitos civis foi rápido. [...] Em março o parlamento - sem os representantes da esquerda e da socialdemocracia, que haviam sido presos ou afastados de suas funções - aprovou o direito de Hitler legislar sem a interferência do legislativo. Partidos, sindicatos e 
jornais de oposição foram fechados e seus líderes presos. (CAMPOS et al., 2016, p. 69).

As referências citadas ao longo do texto são acadêmicas. As definições em boxes são de autores que produzem para público não escolar: o antissemitismo é definido por Annette Wieworka, historiadora francesa especialista no Holocausto. Em destaque para uso exclusivo do professor, os autores lembram que o discurso antissemita se manifestou também no Brasil, indicando referência em capítulo posterior, além de tratarem do uso político feito por Hitler e pelos nazistas do sentimento antijudaico presente na sociedade alemã do período. Palavras destacadas em negrito ao longo do texto, Benito Mussolini, fascistas, Giacomo Matteoti, corporativismo, República de Weimar e totalitarismo, não são retomadas em glossário ou em boxes explicativos. Hannah Arendt é mais uma vez lembrada como tradutora dessa "lógica de controle absoluto num conceito: totalitarismo" (CAMPOS et al. 2016, p. 69), questão já analisada por nós.

No último parágrafo do texto, os autores destacam o sentido mítico e atemporal da ideologia nazista fazem uma referência a Umberto Eco e afirmam: "o repertório temático e o efeito das obras era essencialmente mítico, dirigido a um mundo em que homens e mulheres desempenhavam papeis fixos e constantes" (CAMPOS et al., 2016, p. 70).

Em relação aos sujeitos históricos, os autores de a Oficina de História reforçam que a ação histórica é realizada por homens, sejam eles indivíduos ou grupos sociais: "Mussolini também iniciou um processo de militarização do movimento, com a criação dos camisas-negras. Proprietários rurais e industriais enxergavam, em Mussolini, um líder capaz de combater um eventual avanço socialista" (CAMPOS et al., 2016, p. 66).

Para a continuidade do estudo, são sugeridos filmes - como $O$ triunfo da vontade, de 1934, A onda, de 1981, e Concorrência desleal, de 2000 - e a obra Massa e poder, de Elias Canetti. Assim, ao mesmo tempo em que se atende a uma prescrição do PNLD, a de orientar professores e alunos para a continuidade de estudos sobre os temas estudados, estabelece-se o olhar dos autores sobre a relação do passado histórico com o presente - as implicações históricas do acontecimento nazismo permanecem presentes.

Os exercícios se localizam ao final do texto-base, diferenciando de forma explicita o conteúdo conceitual a ser aprendido. Na seção Verificação de leitura, questões organizam a leitura e o estudo do aluno. As seções dos capítulos têm a função de ajudar o aluno "a desenvolver um tipo de conhecimento e habilidade" - todos os 
exercícios, inclusive os dos exames classificatórios para a entrada nas universidades, são acompanhados com legendas indicando as habilidades e competências, segundo a matriz de referências do ENEM.

\section{Considerações finais}

A análise das narrativas desses livros didáticos nos possibilita entender que a definição dos saberes privilegiados como elementos da cultura (a ser compartilhada por grupos sociais) em uma determinada época responde a interesses de classes sociais, grupos e indivíduos em cada momento histórico.

Os autores, narradores do passado, constroem suas narrativas considerando as intenções e a materialidade do livro que determinam formas de escrita e de leitura, projetando uma sociedade a ser edificada. Examinamos que a relação que estes estabelecem com o passado é não só norteada por suas escolhas epistemológicas, mas também pelos objetivos educacionais e pedagógicos prescritos e legitimados nos currículos de ensino. Nosso olhar procurou se dirigir às maneiras como os diferentes autores dão sentido ao passado, transformando especificamente os acontecimentos históricos Fascismo e Nazismo em um saber ensinável, criando analogias, propondo metodologias de aprendizagem, construindo relações temporais e estabelecendo finalidades de aprendizagem.

Pudemos constatar que as atividades didáticas ${ }^{24}$ ganham força nesses materiais com a proposição de diversos tipos de exercícios: múltipla escola, retirados de exames vestibulares e do ENEM; pergunta e resposta, que orientam leituras e relações dos alunos com os diferentes materiais disponibilizados. Alguns referem-se ao texto principal, destacando aspectos a serem compreendidos, outros destacam conceitos e contextualizações a serem compreendidas a partir dos textos historiográficos. Questões de entendimento de textos jornalísticos inserem a vida cotidiana do cidadão no passado estudado ou propõem atividades que relacionam o acontecimento estudado com o presente vivido. Os exercícios têm adquirido maior espaço físico e maior complexidade nas coleções didáticas, indício de que a centralidade das práticas pedagógicas está cada vez mais na ação dos alunos e na sua leitura compreensiva e crítica sobre obras

\footnotetext{
${ }^{24}$ A pesquisa sobre os exercícios na conformação da História como disciplina escolar tem se acentuado nos últimos anos no campo do ensino de História. Chamamos a atenção para a importância desse tema que tem se tornado fundamental para o entendimento das instituições e dos saberes escolares, submetidos a testes e avaliações anuais, realizadas por instituições ligadas a financiamentos e investimentos globais. A esse respeito ver (FARICELLI, 2005).
} 
produzidas no passado visitado. A destacar, nesse sentido, a proposta de análise de imagem da obra Alicerces da sociedade, de George Grosz, reproduzida na Oficina de História, que não é comentada ao longo do texto didático e, por isso, não foi reproduzida neste artigo. A imagem deixa de ser ilustração, reforço - dependendo do objetivo e da ação do docente, pode representar o olhar do aluno ou do grupo de alunos sobre o passado visitado.

Rejeita-se, pelo menos na intenção, a tradição, em muitos casos ainda presente na realidade de salas de aula, da memorização como método privilegiado de aprendizagem da História. Essas atividades, elaboradas, corrigidas e avaliadas pelos professores no seu dia a dia relacionam-se diretamente à ação dos alunos, pertencendo ao que Perrenoud (1995) denomina "ofício do aluno". Segundo esse autor, trata-se de "práticas verdadeiramente escolares, cuja finalidade é a de estimular a compreensão, a memorização, a consolidação, a generalização de certas noções, métodos ou conhecimentos" (PERRENOUD, 1995, p. 21). Referem-se ao que Monteiro (2001) define como o saber pedagógico da disciplina ligado ao fazer docente.

Em um momento que a instituição escolar tem sido questionada por setores conservadores da sociedade brasileira, problematizar esquecimentos e presenças, que compõem narrativas históricas a partir de acontecimentos do passado, tem se tornando um exercício cada vez mais necessário aos profissionais ligados ao ensino de História. Dar sentido ao que aconteceu anos atrás, escolher e reunir fatos que se tornam referências ao vivido, demonstra que a presença e o entendimento de acontecimentos do passado no presente são dinâmicos, constantemente refeitos em grande parte das aulas de História. Nesse processo, sujeitos, fatos e processos são revisitados, relidos. Novos objetos, fontes e metodologias de análise são incorporados ao estabelecido; outros são deixados de lado, esquecidos pela pequena relevância momentânea.

\section{Referências}

\section{Fontes}

BRASIL. Ministério da Educação. PNLD 2018: história - guia de livros didáticos Ensino Médio/ Ministério da Educação - Secretária de Educação Básica - SEB - Fundo Nacional de Desenvolvimento da Educação. Brasília, DF: Ministério da Educação, Secretária de Educação Básica, 2017.

CAMPOS, F. et al. Oficina de história: volume 3. São Paulo: Leya, 2016.

VAINFAS, R. et al. História. São Paulo: Saraiva, 2016. 


\section{Bibliografia}

ALBERTI, V. O professor de história e o ensino de questões sensíveis e controversas. Palestra proferida no IV Colóquio Nacional História Cultural e Sensibilidades, realizado no Centro de Ensino Superior do Seridó (Ceres) da Universidade Federal do Rio Grande do Norte (UFRN), em Caicó (RN), de 17 a 21 de novembro de 2014.

ARAUJO, E. Ministro diz que fascismo e nazismo eram de esquerda e gera polêmica. Disponível em: https://g1.globo.com/jornal-nacional/noticia/2019/03/29/ministro-dizque-fascismo-e-nazismo-eram-de-esquerda-e-gera-polemica.ghtml. Acesso em: 3 abr. 2020.

BITTENCOURT, C. Livros didáticos entre textos e imagens. In: O saber histórico na sala de aula. São Paulo: Contexto, 2006.

. Livro didático e saber escolar (1810-1910). Belo Horizonte: Autêntica, 2008a.

Ensino de história: fundamentos e métodos. São Paulo: Cortez, 2008 b.

Produção didática de História: trajetórias de pesquisas. Revista de História, São Paulo, n. 164, p. 487-516, jan./jun. 2011.

CASSIANO. C. C. F. O mercado do livro didático no Brasil do século XXI: a entrada do capital espanhol na Educação Nacional. São Paulo: Editora Unesp, 2013.

CHARTIER, R. A história cultural: entre práticas e representações. Lisboa: Difel, 1990.

CHERVEL, A. História das disciplinas escolares: reflexões sobre um campo de pesquisa. Teoria \& Educação, Porto Alegre, v. 2, p. 177-229, 1990.

CHOPPIN. A. O historiador e o livro escolar. Trad. Maria Helena C. Bastos. Revista de História da Educação, p. 5-24, 2002. Disponível em: https://seer.ufrgs.br/asphe/article/view/30596/pdf. Acesso em: 7 abr. 2020.

História dos livros e das edições didáticas: sobre o estado da arte. Educação $e$ Pesquisa, São Paulo, v.30, n.3, p. 549-566, set./dez. 2004

O manual escolar: uma falsa evidência histórica. Tradução: Maria Helena C. Bastos. História da Educação, ASPHE/FaE/UFPel, Pelotas, v. 13, n. 27 p. 9-75, jan./abr. 2009. Disponível em: http//fae.ufpel.edu.br/asphe. Acesso em: 7 abr. 2020.

DENIAL. Mick Jackson. Mick Jackson. Sony Pictures, 2016. Disponível em: https://www.youtube.com/watch?v=yc3PZzTG5oA. Acesso em: 16 mar. 2020.

FARICELLI, M. F. Conteúdo pedagógico da história como disciplina escolar: exercícios propostos por livros didáticos de $5^{\mathrm{a}}$ a $8^{\mathrm{a}}$ série. Dissertação (Mestrado em Educação), Pontifícia Universidade Católica de São Paulo, São Paulo, SP, 2005.

FORQUIN, J. C. Saberes escolares, imperativos didáticos e dinâmicas sociais. Teoria \& Educação, Porto Alegre, n. 5, p. 28-49, 1992. 
GOODSON, I. A construção social do currículo. Porto: Educa, 1997.

JULIA, D. A cultura escolar como objeto histórico. Revista Brasileira de História da Educação, Campinas, n. 1, p. 9-43, 2001.

LAVILLE, C. A guerra das narrativas: debates e ilusões em torno do ensino de História. Revista Brasileira de História, São Paulo, v. 19, n. 38, p. 125-138, 1999.

LE GOFF, J. História e memória. São Paulo: Campinas: Editora Unicamp, 1990.

MIRANDA, S.; DE LUCA. T. O livro didático de história hoje: um panorama a partir do PNLD. Revista Brasileira de História, v. 24, n. 48, p.123-144, 2004.

MIRANDA. S. Aprender e ensinar o tempo histórico em tempos de incertezas: reflexões e desafios para o professor de História. In: GONÇALVES, M. et al. (Org.). Qual o valor da História hoje? Rio de Janeiro: Editora FGV, 2012.

MONTEIRO, Ana Maria. Professores entre saberes e práticas. Educação \& Sociedade, Ano XXII, n. 74, p. 121-142, abr. 2001.

MUNAKATA, K. O livro didático: alguns temas de pesquisa. Revista Brasileira de História da Educação, Campinas-SP, v. 12, n. 3 (30), p. 179-197, set./dez. 2012

Livro didático como indício da cultura escolar. Revista História da Educação (Online), Porto Alegre, v. 20, n. 50, p. 119-138, set./dez. 2016.

NAQUET, P. V. Os assassinos da memória: um Eichmann de papel e outros ensaios sobre o revisionismo. Campinas: Papirus, 1988

PEREIRA, N; SEFFNER, F. Ensino de história: passados vivos e educação em questões sensíveis. Revista História Hoje, v. 7, n. 13, p. 14-33, 2018.

PERRENOUD, P. Ofício de aluno e sentido do trabalho escolar. Porto (Portugal): Editora Porto, 2002.

RALEJO, A. S. "Lugar de autoria": contingências, desafios e possibilidades na produção de livros didáticos de História. 2018. Tese (Doutorado em Educação) Programa de Pós-Graduação em Educação, Universidade Federal do Rio de Janeiro, Rio de Janeiro, 2018.

RICOEUR, P. Tempo e narrativa. Tomo I. Trad. Constança M. Cesar. Campinas: São Paulo: Papirus, 1994.

. A memória, a história e o esquecimento. Trad. Alain François [et al.]. Campinas, SP: Editora da Unicamp, 2007.

ROCHA, H. Livro didático de história em análise: a força da tradição e transformações possíveis. In: de Janeiro: FGV, 2017.

et al. Livros didáticos de história: entre políticas e narrativas. Rio 
ROQUE, T. O negacionismo no poder: como fazer frente ao ceticismo que atinge a ciência e a política. Revista Piauí. Disponível em: https://piaui.folha.uol.com.br/materia/o-negacionismo-no-poder/. Acesso em: 1 ago. 2020.

SÁCRISTAN, J. G. O currículo: os conteúdos de ensino ou uma análise da prática? In: ; GOMEZ. A. I. P. Compreender e transformar o ensino. Trad. Ernani F. da Fonseca Rosa. Porto Alegre: Artmed, 2000.

SILVA, K; V. Fascismo. In: Dicionário de conceitos históricos. São Paulo: Contexto, 2006.

STOPPINO, M. Totalitarismo. In: BOBBIO, N. et al. (org.) Dicionário de política. Trad. Carmen C, Varriale et al. Brasília: Editora Universidade de Brasília, 1998.

VEYNE, P. M. Como se escreve a história: Foucault revoluciona a história. Trad. Alda Baltar e Maria Auxiliadora Kneipp. 4. ed. Brasília: Editora Universidade de Brasília, 1998.

Artigo recebido em 20 de junho de 2020. Aprovado em 07 de agosto de 2020. 